Gabriela LuPIAÑEZ*

Universidad Nacional de Tucumán (Argentina)

gabriela.lupianez@filo.unt.edu.ar, gabriela.lupianez@gmail.com

ORCID iD: http:/ / orcid.org/0000-0002-2176-0522

\title{
Usos de la noción de "pueblo" en Tucumán en tiempos de las invasiones inglesas: mediados de 1806 - mediados de 1808.
}

\section{Uses and meanings of the "people" in Tucumán at the time of the British invasions: Mid-1806 to mid-1808.}

Resumen: Este escrito se propone comprender el modo en que algunos agentes de la élite del pueblo de Tucumán (cabildo y notables), perteneciente al virreinato del Río de la Plata, entendieron y practicaron la relación con las autoridades superiores con sede en Buenos Aires y peninsulares entre mediados de 1806 y mediados de 1808. Un tiempo de "autonomía de hecho" - en el que quienes debían obedecer comenzaron a tomar decisiones sobre el gobierno impensables con anterioridad- que fue el efecto imprevisto de las invasiones inglesas a los dominios más australes de la monarquía hispana. Con ese objeto, se propone indagar sobre los usos (sentidos) de la noción de "pueblo". Esta noción remitía tradicionalmente a un sujeto central en la estructura de la monarquía hispana en América. Sin embargo, pronto debió lidiar con nuevos sentidos. Se plantea que los pueblos tuvieron un rol importante en la defensa de Buenos Aires, así como mantuvieron una relación de reciprocidad con el rey.

Palabras clave: autonomía, soberanía, pueblo/ pueblos, pacto de reciprocidad, invasiones inglesas, independencia.
Summary: This article aims to understand the way some agents in Tucumán, situated in the Rio de la Plata Viceroyalty, understood and recreated their relationship with superior authorities at Buenos Aires and Spain between 1806 and 1808. Because of British invasions to the Rio de la Plata, this was a time of factual autonomy from metropolitan and sub-metropolitan authorities. Hence, peoples in Tucumán experienced an unprecedented degree of self-government. In this context, this paper proposes to look at the ways the notion of "people" was used and deployed by the local cabildo and other local élites. While uses of the notion of "people" were grounded on Hispanic political tradition, this article proposes that the experience at the time of the invasion and the aids given to Buenos Aires opened up the possibility of new ways of understanding this notion -especially in what regarded the bounds of reciprocity between the people of Tucumán and the King.

Keywords: autonomy, sovereignty, British invasions, reciprocity, independence,

\footnotetext{
* Docente en la carrera de Historia de la Universidad Nacional de Tucumán (UNT/Arg.). Realizó estudios de postgrado en ciencias políticas en FLACSO (Bs.As.). Es Magister en Estudios del Mundo Hispano (CSIC/ Madrid) y aspirante doctoral en el Doctorado en Ciencias Sociales (UNT/Arg.).

Título del trabajo: Usos de la noción de "pueblo” en Tucumán en tiempos de las invasiones inglesas. Virreinato del Rio de la Plata, mediados de 1806- mediados de 1808.

ORCID iD: http://orcid.org/0000-0002-2176-0522
} 
Este escrito se propone comprender el modo en que algunos agentes de la élite del pueblo de Tucumán, perteneciente al virreinato del Río de la Plata, entendieron y practicaron la relación con las autoridades superiores de Buenos Aires así como con las de la metrópoli entre mediados de 1806 y mediados 1808.

Un efecto imprevisto de las invasiones británicas al Rio de la Plata fue el inicio de un tiempo de "autonomía de hecho", en el que las instituciones coloniales adquirieron un poder que ya no volvería a manos de la Corona. ${ }^{1}$ Tempranamente en relación con otros territorios de la monarquía hispana, "magistrados y funcionarios [aprendieron] un nuevo tipo de relación con la autoridad suprema en la que es ésta la que solicita... una adhesión que antes ni siquiera se había discutido; les enseñó entonces a descubrir una nueva dimensión más estrictamente política para las actividades de corporaciones y magistraturas". ${ }^{2}$

Así, al interior de algunos pueblos, viejos y nuevos agentes encontraron resquicios en el orden virreinal que les permitieron desarrollar una actividad política inimaginable poco tiempo atrás. Éstos procuraron modificar el equilibrio de poder existente entre los pueblos y las autoridades superiores. Expresiones de esta nueva situación fueron los movimientos producidos en diversos puntos del virreinato, que cuestionaron a las autoridades con sede en Buenos Aires mas no a la autoridad del rey. El movimiento de Buenos Aires iniciado con el cuestionamiento de la acción del virrey ante las invasiones inglesas $(1806 / 7)$ fue seguido, en el contexto de la acefalía real, por el de Montevideo (1808), La Plata y La Paz (1809). Los movimientos realizados a ambos lados del Rio de la Plata tuvieron éxito, mientras que los del Alto Perú fueron reprimidos y fracasaron. ${ }^{3}$

\footnotetext{
1 Tulio Halperín Donghi, Revolución y guerra. Formación de una élite dirigente en la Argentina criolla (Siglo XXI Editores: Buenos Aires, 1979) 137-138.

2 Marcela Ternavasio, Historia de la Argentina, 1806-1852 (Buenos Aires: Siglo XXI Editores, 2009) 38; Ternavasio, Marcela, "De la crisis del poder virreinal a la crisis del poder monárquico. Buenos Aires, 1806-1810", en En el umbral de las revoluciones hispánicas. El bienio 1808-1810, Roberto Breña (México/Madrid: El Colegio de México/Centro de Estudios Políticos y Constitucionales, 2010), 265-299.

3 Ana Frega Novales, "Montevideo ante la crisis de 1808", en Las experiencias de 1808 en Iberoamérica, Alfredo Ávila y Pedro Pérez Herrero, compiladores (México: Universidad de Alcalá/Universidad Autónoma de México, 2008) 535-557; María Luisa Soux Muñoz Reyes, "La Audiencia de Charcas y los acontecimientos de 1808: rumores y tensiones en una sociedad provincial", en Las experiencias de 1808 en Iberoamérica, Alfredo Ávila y Pedro Pérez Herrero, compiladores (México: Universidad de Alcalá/Universidad Autónoma de México, 2008) 465-489; Sergio Serulnikov, "El Alto Perú en la independencia del Río de la Plata", en Crear la Independencia. Historia de un problema argentino, Gabriel Entin editor (Buenos Aires: Capital Intelectual, 2016) 95-125.
} 
En contraposición a lo relatado, la historiografía que se ocupó del caso tucumano puso de relieve la relación de adecuación del pueblo de Tucumán a las iniciativas de las autoridades con sede en Buenos Aires. Al menos desde los tiempos de implantación del régimen de Intendencias esta estrategia común a otros pueblos permitió a la ciudad subordinada de Tucumán escapar del control de Salta, capital de la intendencia de Salta de Tucumán. ${ }^{4}$ Entonces, en el contexto inédito en que "la autoridad suprema es la que solicita una adhesión que antes no se había discutido", ¿qué tipo de relación promovió el pueblo de Tucumán con las autoridades superiores?

El comportamiento del pueblo de Tucumán en tiempos de las invasiones inglesas no pareció defraudar la tendencia referida por la historiografía que se ocupó del caso tucumano. Procuró fortalecer su posición relativa respondiendo favorablemente a sus requerimientos. Si bien podría argumentarse que se trataba de un cálculo racional de intereses, lo hizo justificándolo en la concepción de poder vigente. Así se mantuvo leal a su rey y continuo siendo respetuoso de la jerarquía tradicional como parte de una relación de mutua reciprocidad.

Se trata entonces de revisar las decisiones tomadas por la élite local en el nuevo contexto autonómico. Esta tarea se apoya en una renovada historiografía política centrada en las "revoluciones de independencia". Ésta se ha preocupado por las alternativas de reordenación del poder en tiempos de crisis de la monarquía, entendiendo que esas convulsiones en los territorios americanos fueron efecto de la crisis y no de voluntades de naciones previamente existentes. Por otra parte, la historiografía puso de relieve el rol de los "pueblos" en la monarquía hispana. ${ }^{5}$

\footnotetext{
4 Gabriela Tío Vallejo, Antiguo Régimen y Liberalismo. Tucumán, 1770-1830(San Miguel de Tucumán: Facultad de Filosofía y Letras/ Universidad Nacional de Tucumán, 2001); Irene Garcia De Saltor, La construcción del espacio político. Tucumán en la primera mitad del siglo XIX (Tucumán: Fac. Filosofía y Letras/Universidad Nacional de Tucumán, 2003); José Carlos Chiaramonte, Ciudades, provincias, Estados: orígenes de la Nación argentina (1800-1846) (Buenos Aires: Ariel Historia, 1997).

5 Existe una muy vasta bibliografía respecto de las independencias desarrollada en las últimas tres décadas. A modo de ejemplo, se citan las obras que fueron referentes iniciales de esta prolífica corriente historiográfica. FrançoisXavier Guerra coordinador, Modernidad e independencias. Ensayos sobre las revoluciones hispánicas (México: Mapfre/Fondo de Cultura Económica, 1992); Annino, Antonio, "Soberanías en lucha", en Inventando la nación. Iberoamérica siglo XIX, Antonio Annino y François-Xavier Guerra coordinadores, (México: Fondo de Cultura Económica, 2003), 229253; Jaime Rodríguez O., La independencia de la América Española (México: El Colegio de México/Fondo de Cultura Económica, 1996); Tulio Halperín Donghi, Reforma y disolución de los imperios ibéricos: 1750-1850 (Madrid: Alianza, 1985); Tulio Halperín Donghi, Tradición política española e ideología revolucionaria de Mayo (Buenos Aires: Centro Editor de América Latina, 1985); José Carlos Chiaramonte, Nación y estado en Iberoamérica. El lenguaje politico en tiempos de las independencias (Buenos Aires: Sudamericana, 2004), José Carlos Chiaramonte, Fundamentos políticos e intelectuales de las independencias. Notas para una nueva bistoria intelectual de Iberoamérica (Buenos Aires: Teseo, 2010).
} 
Una noción útil para "medir" la "politización" de las actividades de corporaciones es la de "pueblo". Con fines analíticos se distinguen dos planos en su uso. El primero refiere al "pueblo" de Tucumán como agente sociológico preexistente según la antigua constitución hispana. Este sentido remitía a una comunidad local territorial considerada natural, sujeto de derechos particulares, con autoridades, jerarquía y ordenamiento sociopolítico específico. Fueron éstas las que hicieron un aporte decisivo en el rechazo de los invasores británicos. El segundo alude a la noción en su configuración retórica. Con la acefalía monárquica y la retroversión de la soberanía en mayo de 1810 en un cabildo abierto en Buenos Aires, esa voz se volvió objeto de disputa en la medida en que se transformó en fundamento último del poder. A partir de este momento, la disputa remitió en gran medida a "pueblo" como agente discursivo al que había que dar encarnadura material y que entraría en tensión con el sujeto sociológico de la antigua constitución hispana. Esa figura retórica intentaba dar cuenta no solo de las expectativas de relación del pueblo de Tucumán con las autoridades superiores, sino también respecto de quiénes componían ese pueblo sobre el que se había de gobernar y quién se erigía en su legítimo portavoz.

En este sentido, los aportes de la historia de los conceptos resultan de suma utilidad, sin ser excluyentes en el planteo metodológico. Si bien la conformación de "singulares colectivos", como la noción de "pueblo", remiten a procesos de larga duración, en este estudio centrado en la corta duración de la coyuntura política, se apela a algunos elementos útiles de esta tradición historiográfica. En primer lugar, se asume que "cualquier cosa que pueda y deba ser conceptualizada se encuentra fuera de los conceptos. [De modo que] toda semántica apunta más allá de si misma". " Afirmación que habilita al análisis de los dichos en los discursos, pero también el modo en que los comportamientos de los contemporáneos construyeron sentidos. En segundo lugar, se entiende que los conceptos involucran un "espacio de experiencia" así como un "horizonte de expectativas", categorías meta históricas que permiten dar cuenta del cambio del tiempo histórico. La distancia entre una y otra da cuenta de ese tiempo nuevo que es la modernidad. ${ }^{7}$

El trabajo revisa entonces las respuestas de la élite tucumana a las iniciativas de las autoridades que competían por mayores cuotas de poder (virreyes, cabildo porteño, milicias). Las decisiones se tomaron en un contexto

\footnotetext{
Reinhart Koselleck, "Historia de los conceptos y conceptos de historia", Ayer, No.53 (2004):36.

Reinhart Koselleck Futuro pasado. Para una semántica de los tiempos históricos (Barcelona: Paidós, 1993) 343.
} 
particular de "autonomía de hecho", atendiendo la adhesión (o no) a iniciativas gestadas por dichas autoridades. En ese sentido, se consideran los dichos y comportamientos de capitulares y notables de la ciudad. Se procura identificar al sujeto de la soberanía, los ámbitos y canales de expresión así como el sentido asignado a su acción. Las fuentes documentales revisadas, éditas e inéditas, se encuentran dispersas en diversos repositorios. La información que ofrecen es más escasa de lo que sería deseable en el análisis de los sentidos asignados a la noción de "pueblo" para este periodo en particular.

Este escrito se organiza en dos apartados. El primero permite conocer las identificaciones y estrategias de ampliación de atributos de poder por parte del pueblo tucumano, en tiempos de las invasiones británicas a la capital del virreinato rioplatense. El segundo propone un balance respecto de los usos de la noción de pueblo y las expectativas de vínculo político con las autoridades superiores entre mediados de 1806 y mediados de 1808.

\section{Un "interesante servicio al Rey y a la Patria" (mediados de 1806 - mediados de 1808).}

El 27 de junio de 1806 las tropas británicas ocuparon la ciudad de Buenos Aires y nombraron gobernador al General William Carr Beresford. ${ }^{9}$ Dos días antes, mientras los británicos desembarcaban al sur de la ciudad de Buenos Aires, el virrey Rafael de Sobremonte y Núñez requería auxilio militar a los pueblos del virreinato mientras marchaba a una nueva sede -provisoria- de gobierno, Córdoba. Sobremonte seguía un plan previamente definido por las autoridades metropolitanas en caso de acciones agresivas contra el Rio de la Plata.

La orden del virrey fue reenviada por el comandante de armas de Córdoba a los comandantes de milicias de las ciudades más próximas como Mendoza, San

8 Acta del Cabildo de Tucumán, 08 de febrero de 1807, en Larrouy, Antonio, Documentos del Archivo General de Tucumán. Invasiones inglesas y revolución (Buenos Aires: Imprenta Juan A. Alsina, 1910) 37-38. En adelante LADAGT.

9 Sobre las invasiones inglesas al Rio de la Plata, ver Klaus Gallo, Las Invasiones Inglesas (Buenos Aires: Eudeba, 2004). 
Luis, Santiago y Tucumán. ${ }^{10}$ Las ciudades de Córdoba, Santiago y Tucumán, se hallaban sobre la ruta que unía el puerto de Buenos Aires con las minas de Potosí, sobre el camino conocido como "camino real" o "camino del Perú".

La pequeña ciudad de San Miguel de Tucumán -de alrededor de cuatro mil habitantes-, ubicada en el llano, con importante actividad mercantil, famosa por sus cueros, troperos y construcción de carretas, respondió rápidamente a la solicitud del virrey. A comienzos de julio de 1806, el cabildo local alentaba una activa participación local en términos de donaciones, contribuciones y voluntarios. ${ }^{11}$ Los hombres que marcharon fueron armados, vestidos y provistos de cabalgaduras con los aportes de vecinos y habitantes de Tucumán. Los apellidos de las familias más ilustres encabezaban las listas de voluntarios. En la primera, José Ignacio de Garmendia, comandante de armas interino, ${ }^{12}$ era secundado por el teniente Diego Aráoz y por Bernabé Aráoz como alférez (aunque días después el nombre de este último ya no figuraba en el listado). Bernabé Aráoz se convirtió luego de 1810 en jefe de las milicias locales y obtuvo grados militares. El capellán era otro conspicuo miembro del poderoso clan Aráoz, Pedro Miguel. Bernabé y Pedro Miguel encabezaron la resistencia local al "ejército del virrey del Perú", junto al ejército patriota liderado por Manuel Belgrano, en la batalla del Tucumán del 24 de septiembre de 1812.

Lideraba la segunda compañía el peninsular Salvador Alberdi, diputado de comercio casado con Josefa Aráoz (quienes pronto serian padres de Juan Bautista, inspirador de la constitución argentina de 1853), hermana de Bernabé. Lo acompañaban Juan Venancio Laguna, en cuya casa materna se declaró la independencia de las provincias del Río de la Plata y Máximo Molina. La tercera tenía por capitán a Manuel Pérez Padilla, comandante de armas en 1810. Su teniente y alférez eran Javier Eugenio Ojeda y Diego Ruiz Huidobro respectivamente..$^{13}$ La mayoría de los nombrados tendría relevante participación en los acontecimientos que sobrevendrían en los siguientes años.

\footnotetext{
10 Según Ordenanza de 1782, el virrey tenía el mando directo de los comandantes que estaban al margen de autoridad de los cabildos. Fradkin, Raúl O., "Notas para una historia larga: comandantes militares y gobierno local en tiempos de guerra", en Un nuevo orden político. Provincias y Estado Nacional, 1852-1880, Beatriz Bragoni y Eduardo Miguez, coordinadores (Buenos Aires: Biblos, 2010) 300.

11 Carlos Páez de la Torre, Historia de Tucumán (Buenos Aires: Plus Ultra, 1987); Lucio Reales, Tucumán y las invasiones inglesas (San Miguel de Tucumán, Ediciones Fegamar, 1987); Ventura Murga, "Las invasiones inglesas y Tucumán”, Revista de la Junta de Estudios Históricos de Tucumán I, no. 1 (1968), 123-138.

12 Según se desprende de nota del Comandante de armas interino José Ignacio Garmendia al subdelegado de Real Hacienda Bartolomé Aráoz, Tucumán 15 de julio de 1806, LADAGT, 2-4

13 LADAGT, 2-16.
} 
A fines de julio marcharon desde Tucumán tres compañías milicianas de más de cien voluntarios cada una, provenientes tanto de la ciudad como del campo. Éstas fueron financiadas con el ramo de sisa, ${ }^{14}$ un recurso municipal creado originalmente para la defensa contra el indígena. Se utilizaba para resolver problemas locales sólo en situaciones excepcionales. En la acción del "pueblo" de Tucumán se reconocía a éste en su sentido más literal, aquel que daba cuenta de los habitantes de un territorio conformando una comunidad natural cuya cabeza era el cabildo.

La preocupación por la extensión de la ocupación británica al resto del virreinato llevó al virrey a encargarse, no solo de la organización de la resistencia y reconquista de Buenos Aires sino también de mantener el orden y el control sobre los territorios bajo su autoridad. Por ello emitió una proclama en la que ordenaba que ninguna medida promulgada por las autoridades residentes en Buenos Aires fuera acatada, aun cuando procediera de tan altas magistraturas como la Real Audiencia, el Consulado o los tribunales. ${ }^{15}$ En la misma, el virrey advertía sobre la alteración de la paz y el orden por parte de emisarios británicos. Éstos eran sindicados como "Enemigos de Dios, y del Rey, con ideas contrarias a nuestra Religión Santa, según que lo lloran y lamentan ya los habitantes de Buenos Aires subyugados". "La definición del enemigo dada por la autoridad virreinal se componía de atributos que cuestionaban los pilares constitutivos de la nación española: un cuerpo católico aglutinado en torno a una monarquía católica. ${ }^{17} \mathrm{La}$ apelación a estos recursos retóricos para generar cohesión ante la invasión reflejaban los miedos a que se enfrentaban. Sin embargo, éstos no se plasmaban -como suele ocurrir- de igual manera en la realidad, ya que los invasores habían garantizado a autoridades, vecinos y habitantes sus derechos y privilegios e incluso la protección de la religión católica. De hecho, el cabildo, la Audiencia y la Iglesia porteñas permanecieron en funciones. Las cuestiones que más concretamente cuestionaban el orden virreinal fueron la exigencia del reconocimiento de la soberanía británica y la imposición de un decreto de libertad de comercio que afectó al estrecho pero poderoso círculo de comerciantes ligados al monopolio.

\footnotetext{
14 Según se desprende de nota del Comandante de armas interino José Ignacio Garmendia al subdelegado de Real Hacienda Bartolomé Aráoz, Tucumán 15 de julio de 1806, LADAGT, 2-4.

15 Marcela Ternavasio, Historia de la Argentina, 1806-1852 (Buenos Aires: Siglo XXI Editores, 2009) 27.

${ }^{16}$ El bando había sido emitido un mes después del primero y era remitido por el gobernador intendente al cabildo tucumano, con fecha 28 de julio. Rafael de la Luz al Cabildo de Tucumán, Salta 28 de julio de 1806, LADAGT, p.11.

17 José María Portillo Valdés, Revolución de Nación. Orígenes de la cultura constitucional en España, 1780-1812 (Madrid: Boletín Oficial del Estado/Centro de Estudios Políticos y Constitucionales, 2000).
} 
Si bien la mayoría de los vecinos porteños no reconocieron la soberanía británica impuesta por la conquista, hubo un reducido grupo de criollos ilustrados que mantuvo algún contacto con los invasores sin que quede en claro qué expectativas tenían. Algunos entendieron que el plan habría sido "poner a esta capital en una independencia formal", mientras que otros sostuvieron que ésta se realizaba "negando la obediencia a España, con el auxilio de Gran Bretaña". ${ }^{18}$ Lo cierto es que la indecisión británica -producto de la inconsulta iniciativa de invadir el suelo español- junto a la demora en recibir refuerzos; activaron el ánimo de recuperar la ciudad por parte de los vecinos y el distanciamiento del "partido de la independencia". ${ }^{19}$ Con todo, la noción de "independencia" iniciaba una temprana politización en el Rio de la Plata en comparación con lo sucedido en el resto de los territorios americanos de la monarquía hispana. ${ }^{20}$

En el camino hacia Buenos Aires, las tropas tucumanas se enteraron de la reconquista de la capital a manos de los vecinos porteños, tropas y milicias compuestas por rioplatenses de ambas orillas. ${ }^{21} \mathrm{La}$ "Primera Compañía de Caballería del Regimiento de Voluntarios de Tucumán”, comandada ahora por José Ignacio Garmendia y secundada por Juan Venancio Laguna y Diego Aráoz, fue la encargada de escoltar hasta Tucumán, a doscientos prisioneros británicos. En coordinación con el ayudante mayor de Tucumán, Juan Ramón Balcarce -quien había obtenido el cargo en 1804 siendo trasladado

18 Alejandra Pasino, "Argentina/Río de la Plata"; en Diccionario Político y Social del mundo Iberoamericano. Conceptos politicos fundamentales, 1770-1870 [Iberconceptos II], Javier Fernández Sebastián, director (Madrid: Universidad del País Vasco/Centro de Estudios Políticos y Constitucionales, 2014) 34-35.

19 Fabio Wasserman, Juan José Castelli. De súbdito de la corona a líder revolucionario (Buenos Aires: Edhasa, 2011) 51-59; Marcela Ternavasio, Historia de la Argentina, 1806-1852 (Buenos Aires: Siglo XXI Editores, 2009) 27-29.

${ }^{20}$ Esta es una constatación realizada por Alejandra Pasino. Según Marcela Ternavasio, en el Río de la Plata la noción de independencia adoptaba diversos significados que podían ser atribuidos no sólo a "sujetos supuestamente portadores de ideas radicales extraídas de las revoluciones norteamericana o francesa, sino también a las propias autoridades coloniales ... [como] el virrey interino Liniers, a quien su condición de francés lo condenaba de antemano a ser sospechado de cómplice de Napoleón, como los miembros del cabildo capitalino, imputados por algunos de representar al partido español y de querer formar una junta independiente de la metrópoli, por el abandono en que ésta había dejado al Río de la Plata". Alejandra Pasino, "Argentina/Río de la Plata"; en Diccionario Político y Social del mundo Iberoamericano. Conceptos políticos fundamentales, 1770-1870 [Iberconceptos II], Javier Fernández Sebastián, director (Madrid: Universidad del País Vasco/Centro de Estudios Políticos y Constitucionales, 2014), 33-48; Marcela Ternavasio, "De la crisis del poder virreinal a la crisis del poder monárquico. Buenos Aires, 1806-1810", en En el umbral de las revoluciones hispánicas. El bienio 1808-1810, Roberto Breña (México/Madrid: El Colegio de México/ Centro de Estudios Políticos y Constitucionales, 2010).

${ }^{21}$ El aporte de las tropas orientales habría sido fundamental, según Juan Carlos Luzuriaga. Este autor considera se ha subvalorado el aporte realizado por Montevideo a la reconquista porteña en 1806 principalmente por la historiografía del lado occidental del Río de la Plata. Juan Carlos Luzuriaga Contrera, La reconquista de Buenos Aires. El cenit de Montevideo colonial (Montevideo: Planeta, 2017) 237. 
a la comandancia general de Tucumán-, ${ }^{22}$ el cabildo tucumano obedecía la orden del virrey Sobremonte emitida en las cercanías de Buenos Aires. ${ }^{23}$ En estas novedosas circunstancias, el cabildo de San Miguel de Tucumán, debió mantener de su propio peculio a la mitad de los prisioneros ingleses destinados al interior.

Poco antes, el 14 de agosto de 1806, un cabildo abierto realizado en Buenos Aires con el apoyo de una multitud de vecinos reclamó la renuncia de Sobremonte. El Cabildo de la capital virreinal delegó en Santiago de Liniers el mando militar mientras el político descansó en la Audiencia. Tanto la demanda "popular" como la decisión adoptada fueron inéditas. La resolución fortalecía al Cabildo, a un grupo de presión que se expresaba por fuera del ámbito capitular así como a las recientemente creadas milicias. A partir de ese momento, la comunidad de Buenos Aires contó con una fuerza militar propia que actuaría en adelante no sólo en la defensa de la ciudad sino también como grupo de presión en la toma de decisiones locales.

En febrero de 1807 los británicos ocupaban Montevideo y nuevos refuerzos ingleses llegaban en mayo con el teniente general John Whitelocke a la cabeza. El cabildo de la capital virreinal solicitaba auxilio económico a su par tucumano, a la vez que procuraba reforzar su rol de cabeza del virreinato. Posicionado en el rol de "madre agobiada y afligida", el cabildo de Buenos Aires dejaba en claro que estaba a la cabeza del orden virreinal a pesar del apuro económico y del cambio poco ortodoxo de la autoridad superior del virreinato durante las invasiones. Señalaba que enfrentaba al enemigo británico con recursos propios para que "con sus sacrificios se salvasen sus hermanos". Apelando a la imagen de la familia, corporación originada en el "orden natural”, el ayuntamiento porteño reforzaba la noción de orden según la cual el resto de los pueblos rioplatenses se constituía en hermanos. Era su deber como "madre" sostener la defensa de Montevideo, la "hija muy amada" que

\footnotetext{
22 Balcarce hacía referencia en sus memorias a su paso por Tucumán. En los documentos Balcarce figuraba en diciembre con el cargo de ayudante mayor mientras que a comienzos de marzo se lo menciona como comandante. Carlos Páez De La Torre (h) y Sara Peña De Bascary, Porteños, provincianos y extranjeros en la batalla de Tucumán (Buenos Aires: CIUDAD/Emecé, 2012) 117; "El teniente tesorero de real Hacienda de Tucumán al Tesorero Principal de Salta” y "El cabildo de Tucumán al intendente gobernador y capitán general”, Diciembre 24 de 1806 y Marzo 6 de 1807, LADAGT, 31 y 51 respectivamente. "Balcarce en su vida pública”, en Senado De La Nación, Biblioteca de Mayo. Colección de Obras y Documentos para la Historia Argentina, Tomo II. Autobiografías (Edición Especial en Homenaje al 150 aniversario de la Revolución de Mayo de 1810: Buenos Aires, 1960) 1760-1777.

${ }^{23}$ La orden disponía la distribución de un total de cuatrocientos presos británicos repartidos entre las poblaciones de La Carlota (50), San Luis (50), Santiago del Estero (100) y Tucumán (200). Marqués de Sobremonte al Cabildo de Tucumán, San Nicolás de los Arroyos, Septiembre 7 de 1806 y "Lista de la Primera Compañía de caballería del Regimiento de Voluntarios de Tucumán”, Septiembre 15 de 1806, LADAGT, 17; 18 -19;31 y 32.
} 
estaba ocupada por tropas británicas. ${ }^{24}$ Este lenguaje amoroso que proviene del sentimiento que da sustento a la familia se aplicaba - en este caso- a la relación del rey hacia sus súbditos, ofreciendo una justificación amable de su poder. Quedaba - asimismo- establecido, el lugar que correspondía a cada pueblo en la jerarquía virreinal, postulando que la vulnerabilidad porteña era circunstancial. Los pueblos rioplatenses eran presentados como iguales o "hermanos", aunque de hecho estuvieran subordinados en la jerarquía virreinal. La ciudad-puerto Montevideo, rival de la hegemonía porteña, era considerada una "hija", indicándose así el rol de subordinada que le correspondía a la ciudad de la Banda Oriental del Uruguay.

Como ocurriera anteriormente con la del virrey, la solicitud del cabildo porteño tuvo una rápida respuesta tucumana. Los regidores tucumanos convocaron a los "vecinos de más lustre y distinción que han obtenido y obtienen los empleos más honoríficos de este Pueblo"; con su voto se tomó la decisión de costear una expedición de doscientos hombres, con dos meses de sueldo, equipados con uniforme, viáticos, caballo y armas. El cabildo local puntualizaba que aquel esfuerzo había sido decidido como un "interesante servicio al Rey y a la Patria" 25 , lo que no había hecho con anterioridad. Una actitud que, según el patrón de comportamiento de la época, portaba la expectativa de que el esfuerzo obtuviese una oportuna retribución de parte de la autoridad real en términos de "mercedes" o "gracias". El regimiento de voluntarios de Tucumán pertenecía a la caballería ligera y fue dirigido por Juan Ramón Balcarce, miembro de las tropas regulares asentadas en el virreinato, que obtenía la comisión como comandante de los doscientos hombres aunque al llegar debía subordinarse al jefe de la provincia de Buenos Aires. ${ }^{26}$ Según consigna Gabriela Tío Vallejo, estas tropas tomaron parte en el enfrentamiento con el invasor. ${ }^{27}$

La rápida respuesta tucumana a las demandas capitulares porteñas contrasta con la ofrecida al cuerpo de Patricios que, ante un fisco insolvente, había solicitado -a través de su jefe Cornelio Saavedra- la colaboración económica del cabildo tucumano en la defensa de la capital. ${ }^{28}$ En esa ocasión

\footnotetext{
${ }^{24}$ Cabildo de Buenos Aires al de Tucumán, 27 de enero de 1807, LADAGT, 35-37.

25 Las dos citas del mismo párrafo corresponden a Cabildo de Tucumán, 08 de febrero de 1807, LADAGT, $37-38$.

${ }^{26}$ Expediente de solicitud de ascenso de Juan Ramón Balcarce por el cabildo de Tucumán, abril de 1807, en AGN, Sala IX, 3-5-5, 1791-1809.

27 Gabriela Tío Vallejo, "Campanas y fusiles, una historia de Tucumán en la primera mitad del siglo XIX", en Gabriela Tío Vallejo, coordinadora, La república extraordinaria. Tucumán en la primera mitad del siglo XIX (Rosario: Prohistoria, 2011) 21.

28 Cornelio de Saavedra al Cabildo tucumano, Buenos Aires, Diciembre 30 de 1806, LADAGT, 33.
} 
el ayuntamiento local se excusaba de colaborar con el recientemente creado cuerpo miliciano criollo, que tendría un influjo cada vez mayor en los acontecimientos porteños. ${ }^{29}$

La presencia inglesa en las costas rioplatenses era percibida en Tucumán como un peligro de tal magnitud que su conjuro exigía la activa participación de la comunidad toda, recreando un uso de la noción de "pueblo" muchos más inclusivo de lo que se expresaba a través de canales de comunicación como los bandos y proclamas. Las voces que demandaban auxilio se hacían oír en proclamas dirigidas a un amplio público, que excedía las paredes capitulares, e incluía a grupos tradicionalmente invisibles para las actividades de la "república". Las voces que demandaban auxilio se hacían oír en proclamas dirigidas a un amplio público que excedía las paredes capitulares e incluía a grupos tradicionalmente invisibles a las actividades relativas a la "república". De este modo, no sólo se elevaban voces de autoridades como el alcalde de primer voto, Domingo García, para solicitar la contribución de aquellos que ocupaban un rol secundario en la jerarquía social, sino que también se expresaron quienes estaban restringidas al ámbito del hogar y la familia. Así, las mujeres tucumanas, que aportaron su esfuerzo al sostenimiento del orden conocido, como lo hacía saber una integrante de una familia patricia a sus "compatriotas" femeninas. En ese texto insiste en que debían.

manifestar los sentimientos de patriotismo vasallaje y honor que también nos anima. Aunque la honestidad del sexo nos excluye de la comparecencia personal al socorro de Buenos Aires, no por eso niega otros recursos por demostrar que nuestros deseos se anivelan (sic) con los que han dado a luz los nobles Ciudadanos del Pueblo. La causa de tantos movimientos es común y los perjuicios del azote que nos amaga han de ser trascendentales a todos sin distinción de personas ni estados ${ }^{30}$

A pesar de estar impedidas de participar directamente en las decisiones políticas del momento, la presencia de las mujeres desde el lugar que ocupaban no sólo se tornaba válida sino también necesaria en las circunstancias que se vivían en el Río de la Plata. Éstas podían hacer su aporte al sostenimiento de la causa colectiva ante la amenazaba el orden vigente. En este sentido y

\footnotetext{
2908 de septiembre de 1808, Archivo General de la Nación (en adelante AGN), Sala IX, 3-5-5, 1791-1809.

30 "Proclama de Agueda Tejerina", escrita con letra de Agustín Molina, marzo 10 de 1807 y "Proclama de Domingo García Alcalde ordinario de Tucumán”, marzo 7 de 1807; en LADAGT, 59-60 y 54-55 respectivamente.
} 
respondiendo a la solicitud de Agueda Tejerina -esposa de Manuel Posse, reconocido comerciante peninsular de la ciudad-, ${ }^{31}$ aproximadamente unas cuarenta y ocho mujeres donaron dinero, tela y trabajo de costura como aporte a la causa. ${ }^{32}$ Cabe recordar que, si bien las mujeres gozaban de la condición general de libres, esa libertad no iba necesariamente acompañada de la condición de emancipada, por estar bajo la potestas del padre de familia. Esta condición les inhibía de ser cabeza de familia o independientes, aun cuando hubo casos en que alguna mujer viuda se puso en los hechos a la cabeza de su familia. Esta condición les inhibía de ser cabeza de familia o independientes, ${ }^{33}$ aun cuando hubo casos en que alguna mujer viuda se puso en los hechos a la cabeza de su familia.

El gesto femenino podía equipararse con la participación masculina de los vecinos "respetables", encarnado en el conjunto de los "nobles Ciudadanos". "Ciudadanos", en sentido estricto, eran aquellos que podían ser electos a la vez que podían elegir; integraban tribunales, estaban habilitados para desempeñarse como funcionarios. ${ }^{34}$ Aun reconociendo una diversidad regional importante, los vecinos eran los habitantes varones libres que vivían en la ciudad, eran cabeza de familia con capacidades civiles plenas o que se incorporaban a una comunidad y lo hacían con su familia. También era "vecino" aquel hombre libre que se asentaba en el campo para poblar en calidad de hacendado, comerciante o labrador. Eran el "sustento cívico de la Monarquía" y tenían la obligación de armarse en defensa de la ciudad sede de las autoridades superiores nombradas por el rey. Con todo, no queda claro el grado de inclusión que podría dársele a la frase de Tejerina. En tiempos donde toda colaboración era bienvenida, no convenía enfatizar las diferencias vigentes, sociales y jurídicas. Tal vez la "nobleza" aludida refería solo al gesto positivo que se esperaba de los vecinos en general.

"Ciudadanos nobles" conjuntamente con las mujeres formaban parte del "Pueblo" tucumano y se manifestaban en idénticos sentimientos de "patriotismo", "vasallaje" y "honor". El sentimiento de "patriotismo" -en ese contexto- remitía menos a su uso primigenio de "lugar de origen", que a un

\footnotetext{
31 Francisco Bolsi, "Familias de la élite, revolución y guerra. Una Aproximación al análisis del clan Posse en Tucumán, Argentina, 1810-1830", Secuencia, No.76 (ene-abril 2010): 39-72.

32 Abril (papel roto) de 1807, LADAGT, 60-62.

33 José María Portillo Valdés, "Independencia constituyente", en Las declaraciones de independencia. Los textos fundamentales de las independencias americanas, Alfredo Ávila, Jordana Dym y Erika Pani, coordinadores (México DF: El Colegio de México/ Universidad Autónoma de México, 2013) 487-488.

34 Oreste Cansanello, "Ciudadano/Vecino", en Lenguaje y revolución. Conceptos políticos clave en el Rio de la Plata, 1780 1850, Noemí Goldman, editora (Buenos Aires: Prometeo, 2008), 20-21.
} 
espacio más amplio de límites geográficos difusos, que entrelazaba al pueblo de Tucumán con el de Buenos Aires. ${ }^{35}$ El vínculo de vasallaje, sin dudas, remitía a la relación de subordinación jerárquica que articulaba la comunidad local con el monarca y con ello la lealtad y defensa de las autoridades y territorios bajo su ley. Estos dos principios eran, junto a la religión católica apostólica romana, los fundamentos del orden que en esta sociedad debía conservar un pueblo leal. En tanto "honor", remitía a la legitimidad de la acción pública de las mujeres que, como se mencionó, tenían usualmente por esfera de acción al ámbito del hogar. ${ }^{36}$ El esfuerzo conjunto de los habitantes locales -en sus diversas clases-, aportaba al cometido de evitar que el enemigo inglés se apropiara de los bienes e impusiera sus leyes y su religión al virreinato rioplatense, alterando el orden vigente.

En el norte del virreinato, la amenaza británica tenía un cariz más concreto y cercano. El temor se manifestaba en relación con una posible confabulación de los oficiales ingleses prisioneros en Catamarca con los de Tucumán, en caso de perderse Buenos Aires. Como se sabe, esto no ocurrió. Inmediatamente de conocida la capitulación británica, ciento setenta y cinco prisioneros británicos que habían estado unos diez meses en Tucumán -junto a otros ubicados en Catamarca y Santiago del Estero-, fueron restituidos a Buenos Aires a comienzos de agosto de 1807 bajo la supervisión de Diego Aráoz y con la contribución de los vecinos de la ciudad. ${ }^{37}$ El número de prisioneros no coincidió con los arribados un tiempo antes, lo cual probablemente encuentre explicación en que algunos de estos prisioneros se establecieron en la ciudad, desarrollando actividades lucrativas y casándose con mujeres tucumanas. Este fue el caso de Thomas Elliot. Acompañaba a los prisioneros el gobernador interino José de Medeiros. Éste había sido teniente asesor del gobernador intendente de Salta del Tucumán, Rafael de la Luz, muerto en mayo de 1807. Por esos meses, Medeiros residía en Tucumán, dada su conflictiva relación con el cabildo de Salta, -capital de la intendencia-, y mantenía un buen vínculo con las autoridades y vecinos de la ciudad que le hospedaba.

Más allá de las expectativas tucumanas, lo cierto es que el cabildo porteño reconoció el gesto de su par tucumano; este reconocimiento se manifestó

\footnotetext{
35 Gabriel Di Meglio, "Patriotismo", en Lenguaje y revolución. Conceptos politicos clave en el Rio de la Plata, 1780-1850, Noemí Goldman, editora (Buenos Aires: Prometeo, 2008), 145-158.

${ }^{36}$ Honor: "la acción o demostración exterior por la cual se da a conocer la veneración, respeto o estimación que alguno tiene por su dignidad o su mérito", en Escriche, Joaquín, Diccionario Razonado de Legislación y jurisprudencia, 824; http://bibliohistorico.juridicas.unam.mx/libros/. Fecha de consulta 01.082016.

37 "Expediente sobre la remisión de prisioneros ingleses a la capital de Buenos Aires por comisión del Sr. Gobernador Intendente de la Provincia”, julio 25 de 1807-agosto 17 de 1807, LADAGT, 99-107.
} 
en una relación especial entre ambos, dado que el norteño no sólo había encabezado las acciones de apoyo a Buenos Aires, sino que había superado los aportes realizados por otras ciudades rioplatenses. El cabildo tucumano cumplía con creces con los deberes tradicionales de su pueblo en términos de lealtad, subordinación y conservación de la ley del rey de España, mantenimiento de la religión y defensa de la patria. Era entonces

el primero de la comprensión de este Virreinato que dio pruebas de su lealtad y Patriotismo comprometiéndose a remitir a su costa un cierto número de gentes para la defensa de este Suelo. Él es el que excede en oferta y donativo a todos los demás... El objeto que la anima es la Causa de Dios, del Rey y de la Patria. ${ }^{38}$

Esta declaración iba más allá de la mera retórica. Los aportes financieros por razones bélicas se habían iniciado tempranamente en la primera década del siglo XIX. A medida que la guerra fue más próxima en el espacio, se incrementaron significativamente en número de contribuyentes y en monto total aportado. Los vecinos tucumanos contribuyeron por medio de tres empréstitos voluntarios solicitados por el cabildo local para la guerra contra el inglés, con promesa de devolución. El primero en 1806, en el que participaron no solo setenta y ocho vecinos sino también el gremio de carpinteros. En esta oportunidad se logró recaudar \$1801. Los dos siguientes fueron solicitados entre mayo y junio de 1807 . En mayo se recaudaron $\$ 4280$, contribuyendo 151 vecinos. En junio, por su parte, se duplicó la cantidad de contribuyentes, reuniéndose $\$ 6792 .{ }^{39}$ Los vecinos aportaron $\$ 12.873$, casi una sexta parte de los ingresos públicos de la hacienda tucumana que en 1816 no pasaban de $\$ 80000$ anuales. ${ }^{40} \mathrm{Al}$ parecer, la iniciativa tucumana precedió a la habilitación del gobernador intendente -a diferencia de otros pueblos-, motivando el disgusto de esta autoridad superior. ${ }^{41}$

\footnotetext{
38 Cabildo de Buenos Aires al de Tucumán, marzo 26 de 1807, LADAGT, 77-78.

39 Francisco Bolsi, "La transición del periodo colonial al proceso de revolución e independencia. Una mirada a partir del estudio de los empréstitos solicitados por la guerra en Tucumán, 1810-1820", Revista Historia de América (2010):151-181.

${ }^{40}$ María Paula Parolo, "La construcción de la fiscalidad provincial en la primera mitad del siglo XIX. Tucumán, 1814-1854", en Estado, impuestos y contribuyentes. La construcción del sistema fiscal en Tucumán en el siglo XIX, Paula Parolo y Claudia Herrera, compiladoras (Rosario: Prohistoria, 2016)15-53.

${ }^{41}$ Pablo Sebastián Iramain, "El proceso de independencia a través de las familias principales. Tucumán entre 1810 y 1820”, en Representaciones, sociedad y poder. Tucumán en la primera mitad del siglo XIX, Irene García de Saltor y Cristina del Carmen López compiladoras (Tucumán: Facultad de Filosofía y Letras/Universidad Nacional de Tucumán, 2005) 125.
} 
Lo cierto es que ante la noticia de la reconquista, el cabildo tucumano insistió en la relación de proximidad entre su pueblo y el porteño, en una escala espacial que superaba los límites virreinales para alcanzar a toda la América del Sur. Recurso que permitía exagerar la relación de cercanía y posicionarle, una vez más, en el primer lugar. Pero además, la corporación local se adjudicaba un papel importante en la celebración de la victoria. Los festejos ante la noticia daban cuenta de ello, pues se

llenaron de tanto júbilo a este ayuntamiento y a su fiel vecindario que no es posible puntualizar las demostraciones de contento que practicaron. Aún los jóvenes a ejemplo de los mayores repentinamente ocuparon las calles, y como a porfía daban voces diciendo viva el Rey de España... se puede asegurar... que apenas habrá ciudad en la América Meridional que como ésta haya sentido tan vivamente los trabajos y hostilidades que ha padecido esa Capital: por lo mismo rinde a V.S. las debidas gracias por las mucha parte que ha tenido en este decisivo golpe que supo someter el orgullo del enemigo. ${ }^{42}$

La celebración del triunfo involucraba como novedad la participación de los jóvenes que, respetando la jerarquía, se hacían visibles en relación con la república como anteriormente las mujeres. Pronto, el cabildo tucumano recibió una circular de Liniers en la que le informaba sobre la "gracia" que el monarca había concedido al pueblo tucumano que, "además del dictado de M.N. y M.L se la (sic) dé en adelante tratamiento de Excelencia y sus capitulares gocen el de Señoría". ${ }^{43}$ La " gracia" era una potestad del orden de lo milagroso - no de lo cotidiano como la jurisdicción- que era administrada por el monarca. ${ }^{44}$ Los títulos de "Muy Noble" (M.N) y "Muy Leal" (M.L) junto al "tratamiento de Excelencia" que el rey otorgaba a la ciudad tucumana, venían a dar cuenta del reconocimiento que éste había hecho del servicio presentado por el pueblo tucumano en tiempos de la invasión extranjera. Aunque la documentación no lo aclara, es de suponer que la distinción otorgada por el monarca al pueblo de Tucumán debió ser un reconocimiento a la fidelidad de la ciudad a su monarca. Desde fines de la Edad Media, la concesión de títulos

\footnotetext{
42 Cabildo de Tucumán al de Buenos Aires, agosto 10 de 1807, LADAGT, 107.

43 Esto se informaba en función del conocimiento de la publicación de La Gaceta Extraordinaria del 20 de noviembre de 1807, aunque aún no se había recibido la Real Cédula correspondiente. Circular de Santiago de Liniers al cabildo de Buenos Aires, junio 11 de 1808, AHT. SA, Vol.19, f.163

44 Alejandro Agüero, "Las categorías básicas de la cultura jurisdiccional", en De Justicia de jueces a justicia de leyes: hacia la España de 1870. Cuadernos de Derecho Judicial V T, Marta Lorente Sariñena, Coordinadora (Madrid: Consejo General del Poder Judicial/Centro de Documentación Judicial, 2006)19-58.
} 
por parte del rey a las ciudades recreaba obligaciones mutuas entre ambas partes, originando relaciones similares a las que vinculaban al monarca con la nobleza. Simultáneamente, creaba una jerarquía de ciudades con precedencia en Cortes ${ }^{45}$ y que en los tiempos que corrían, a comienzos del siglo XIX, no conocemos en qué plano se podría llegar a plasmar a nivel de los dominios americanos. Máxime cuando este tipo de lenguaje se entrecruzaba con aquel que postulaba la jerarquía propia de la administración intendencial.

Por supuesto que Tucumán no fue el único pueblo donde la situación de la capital movilizó a la población en general y a sus autoridades. Más allá de las tropas profesionales y voluntarios provenientes de Montevideo y Colonia y de los aportes de los pueblos de la Intendencia de Salta del Tucumán, incluso desde lugares muy lejanos del virreinato hubo una reacción de auxilio a la capital rioplatense. En la ciudad de La Plata (Intendencia de Chuquisaca) mientras la Audiencia reclutaba milicianos para la defensa de Buenos Aires, un cabildo abierto decidía una convocatoria espontánea a la recaudación de fondos en auxilio de Buenos Aires. Sin embargo, ésta fue rechazada por el gobernador intendente y los oidores, suspicaces ante el entusiasmo que en la población local suscitaba el protagonismo de la población porteña en la defensa de la ciudad. ${ }^{46}$ Por su parte, Montevideo también recibió títulos por parte del monarca por su participación en la lucha contra los británicos. ${ }^{47}$

Luego de la capitulación del ejército británico en Buenos Aires y el retiro de las tropas invasoras de Montevideo, Sobremonte fue definitivamente separado de funciones. Para cuando llegó la designación real de Pascual Ruiz Huidobro como virrey, éste se hallaba preso en Inglaterra tras la toma de Montevideo. Por ende, el héroe de la reconquista, el francés Santiago de Liniers, no sólo asumió como brigadier de la Real Armada según disposición real, sino que también se convirtió en virrey interino por ser el oficial de mayor jerarquía en el virreinato rioplatense. Decisión que venía avalada por la nueva normativa emanada por la Corona a comienzos de 1807 según la cual, las vacancias

\footnotetext{
45 Agradezco las explicaciones personales de Andrea Navarro, incondicional enamorada de la historia medieval, respecto a las relaciones bajomedievales entre las ciudades y la monarquía hispana. Andrea Mariana Navarro, Ciudades de Andalucía. Paisajes e Imágenes. Siglos XIII-XVII (Madrid: Comité Español de Ciencias Históricas/ Dykinson, 2017). ${ }^{46}$ Sergio Serulnikov, "El Alto Perú en la independencia del Río de la Plata", en Crear la Independencia. Historia de un problema argentino, Gabriel Entin, editor (Buenos Aires: Capital Intelectual, 2016), 112; María Luisa Soux Muñoz Reyes, "La Audiencia de Charcas y los acontecimientos de 1808: rumores y tensiones en una sociedad provincial", en Las experiencias de 1808 en Iberoamérica, Alfredo Ávila y Pedro Pérez Herrero compiladores (México: Universidad de Alcalá/Universidad Autónoma de México, 2008), 473.

47 Ana Frega Novales, "Montevideo ante la crisis de 1808”, en Las experiencias de 1808 en Iberoamérica, Alfredo Ávila y Pedro Pérez Herrero compiladores (México: Universidad de Alcalá/Universidad Autónoma de México, 2008), 541.
} 
interinas al cargo de virrey debían cubrirse con el jefe militar de mayor en lugar del presidente de la Audiencia. Liniers, fiel funcionario de la monarquía hispana a pesar de las opiniones de sus detractores por su origen francés, era confirmado como virrey interino en diciembre de 1807 por las autoridades peninsulares. Esta resolución se conoció en las costas rioplatenses recién a mediados de mayo de 1808. El cabildo tucumano, por su parte, se notificó de la misma recién en junio de $1808 .{ }^{48}$

En tanto, mientras la Audiencia procuraba encontrar el equilibrio entre sus tradicionales funciones y las circunstancias que le tocaba vivir, a mediados de 1809 un nuevo virrey designado por la autoridad supletoria de la Junta Central arribaba a costas rioplatenses. Su aceptación debía negociarse con los grupos de presión porteños. Pero no sólo eso, la crisis desatada a lo largo y ancho de la extensa monarquía hispana en 1808, demostraría cuán disputada sería la adhesión de los pueblos del virreinato a las autoridades centrales por parte de diversos agentes que procuraban un poder unívoco y centralizado. Aun cuando la autoridad real no estuviera cuestionada sino que, según el derecho vigente, se hallase tutelada por los agentes en disputa bajo la figura de la "retroversión de la soberanía".

${ }^{48}$ El gobernador intendente al cabildo de Tucumán, 02 de junio de 1808, Archivo Histórico de Tucumán, Documentos de la Sección Administrativa (en adelante AHT. SA), Vol. 19, f.159-160 v. 
Esta temprana actividad política no pareció replicarse en el pueblo de Tucumán, en el que no hubo disputa en relación con el reconocimiento de la cadena jerárquica. Claro está, que Tucumán era un pueblo subordinado, mientras aquellos que se opusieron a la autoridades virreinales con sede en Buenos Aires tenían otras posiciones de poder, como es el caso de Montevideo -base naval-o La Plata-sede de Real Audiencia-y de una de las universidades más antiguas de la América Hispana.

El análisis de la noción de "pueblo" en la élite de Tucumán permite constatar que sus habitantes reaccionaban en defensa de la monarquía en tanto "nación hispana", como cuerpo católico observante de la tradicional constitución y leal al monarca español ante la amenaza de un rey, ejército y religión extraños. De hecho, en la lógica de reciprocidad propia de la monarquía hispana, la guerra contra el inglés se convirtió en una oportunidad para procurar extender sus fueros y potestades a partir de los servicios prestados (como ocurriría en septiembre 1812 en un nuevo contexto, el de la guerra civil y revolucionaria). La estrategia del pueblo de Tucumán fue fortalecer su posición construyendo una relación más estrecha con las autoridades superiores de Buenos Aires, ya fuera el antiguo virrey -luego desplazado-, el cabildo de Buenos Aires o el nuevo virrey Liniers. De este modo, el pueblo de Tucumán adhería a quien de hecho ejercía el poder en nombre de un lejano rey que no tenía en la ciudad representante real estable como en épocas anteriores.

De este modo, la noción de pueblo continuó remitiendo a la experiencia de comunidad local territorial en su versión más tradicional, como sujeto sociológico preexistente según la antigua constitución. Sin embargo, la amenaza británica redundó a escala local en la visibilización de agentes y espacio usualmente ausentes. Así, adquiría un lugar todo aquel que demostrara capacidad para aportar a la defensa del territorio de la monarquía: la juventud, las mujeres, el gremio de artesanos, o los habitantes de otros grupos sociales que se convertían en voluntarios milicianos o celebraban triunfos en las calles. Todo el pueblo, en tanto sujeto concreto hecho de corporaciones ordenadas jerárquicamente, aparecía en el espacio de la ciudad escenificado en su diversidad, más allá del cabildo y los sujetos que tenían responsabilidades políticas.

En Tucumán, a diferencia de Buenos Aires, la voz "independencia” no se mencionaba. En cambio, sí apareció la noción de "patria", asociada a la de "pueblo" con un sentido emotivo como observó Wasserman para un espacio 
extenso de la monarquía hispana ${ }^{49}$ más amplio que el estrecho lugar de origen, y que permitió articular un espacio amplio que entrelazaba a Tucumán con Buenos Aires.

El uso de la noción de "pueblo", en la élite tucumana, da cuenta de que no hubo quiebre entre experiencia y expectativas en la medida en que sujeto sociológico y sujeto retórico coincidían. La aparición de un uso retórico ligado a expectativas de futuro diferentes de la experiencia se planteó con posterioridad a mayo de 1810 . Un tiempo en que producto de la acefalía real y de la decisión de un grupo en Buenos Aires, se instauró un poder revolucionario a partir de la retroversión de la soberanía. La experiencia de tres siglos de la antigua constitución fundada en un orden natural se quebraba. Otro fundamento de poder, el de la soberanía popular -fuera en el entendimiento de una soberanía concentrada en el pueblo o de una pluralidad de cuerpos soberanos, los pueblos- aparecía en el horizonte. La noción de pueblo como figura retórica comenzaba a dar cuenta no solo de las expectativas alternativas de relación del pueblo de Tucumán con las autoridades superiores, sino también respecto de quiénes integraban ese pueblo, a quién se debía gobernar.

\section{Fuentes consultadas (éditas e inéditas)}

Escriche, Joaquín. Diccionario razonado de legislación y jurisprudencia, consultado Agosto 1, 2016, https:/ /archive.org/details/diccionariorazon00escr

Larrouy, Antonio. Documentos del Archivo General de Tucumán. Invasiones inglesas y revolución, vol. 1, 1806-1807. Buenos Aires: Comisión del Centenario/ Imprenta Juan A. Alsina, 1910.

Senado de la Nación. Biblioteca de Mayo. Colección de Obras y Documentos para la Historia Argentina, vol. 2, Autobiografias, Edición Especial en Homenaje al 150 aniversario de la Revolución de Mayo de 1810, Buenos Aires: Senado de la Nación, 1960.

Archivo General De La Nación Argentina. Sala IX. Legajo 3-5-5, 17911809.

49 Fabio Wasserman, "El concepto de nación y las transformaciones del orden político en Iberoamérica. 1750-1850", en Iberoamericana. Anuario de Historia de América Latina. Jahrbuch für Geschichte Lateinamerikas, No.45 (2008):197-220. 
Archivo Histórico De Tucumán, Documentos de la Sección Administrativa. Vol. 19, 1806-1808.

\section{Bibliografía}

Agüero, Alejandro. "Las categorías básicas de la cultura jurisdiccional". En De Justicia de jueces a justicia de leyes: hacia la España de 1870. Cuadernos de Derecho Judicial VI, Marta Lorente Sariñena coordinadora, 9-58. Madrid: Consejo General del Poder Judicial/Centro de Documentación Judicial, 2006.

Annino, Antonio. "Soberanías en lucha", en Inventando la nación. Iberoamérica siglo XIX, Antonio Annino y François-Xavier Guerra coordinadores, 229-253. México: Fondo de Cultura Económica, 2003.

Bolsi, Francisco. "Familias de la élite, revolución y guerra. Una Aproximación al análisis del clan Posse en Tucumán, Argentina, 1810-1830”. Secuencia, 76 (ene-abril 2010): 39-72.

Bolsi, Francisco. "La transición del periodo colonial al proceso de revolución e independencia. Una mirada a partir del estudio de los empréstitos solicitados por la guerra en Tucumán, 1810-1820”. Revista Historia de América (2010): 151-181.

Cansanello, Oreste. "Ciudadano/Vecino". En Lenguaje y revolución. Conceptos políticos clave en el Rio de la Plata, 1780-1850, Noemí Goldman coordinadora, 19-34. Buenos Aires: Prometeo, 2008.

Chiaramonte, José Carlos. Ciudades, provincias, Estados: orígenes de la Nación argentina (1800-1846), Buenos Aires: Ariel Historia, 1997.

Chiaramonte, José Carlos. Nación y estado en Iberoamérica. El lenguaje político en tiempos de las independencias, Buenos Aires: Sudamericana, 2004.

José Carlos Chiaramonte. Fundamentos politicos e intelectuales de las independencias. Notas para una nueva historia intelectual de Iberoamérica, Buenos Aires: Teseo, 2010.

Di Meglio, Gabriel, "Patriotismo", En Lenguaje y revolución. Conceptos políticos clave en el Rio de la Plata, 1780-1850, Noemí Goldman coordinadora, 145158. Buenos Aires: Prometeo, 2008. 
Fradkin, Raúl O. "Notas para una historia larga: comandantes militares y gobierno local en tiempos de guerra". En Un nuevo orden político. Provincias y Estado Nacional, 1852-1880, Beatriz Bragoni, y Eduardo Míguez coordinadores, 293-306. Buenos Aires: Biblos, 2010.

Frega Novales, Ana. "Montevideo ante la crisis de 1808”. En Las experiencias de 1808 en Iberoamérica, Alfredo Ávila y, Pedro Pérez Herrero compiladores, 535-557. México: Universidad de Alcalá/Universidad Autónoma de México, 2008.

Gallo, Klaus. Las Invasiones Inglesas. Buenos Aires: Eudeba, 2004.

Garcia De Saltor, Irene. La construcción del espacio politico. Tucumán en la primera mitad del siglo XIX, Tucumán: Facultad de Filosofía y Letras/Universidad Nacional de Tucumán, 2002.

Guerra, François-Xavier coordinador. Modernidad e independencias. Ensayos sobre las revoluciones hispánicas, México: Mapfre/Fondo de Cultura Económica, 1992.

Halperin Donghi, Tulio. Revolución y guerra. Formación de una élite dirigente en la Argentina criolla. Buenos Aires: Siglo XXI editores, 1979.

Halperín Donghi, Tulio. Reforma y disolución de los imperios ibéricos: 1750-1850. Madrid: Alianza, 1985.

Halperín Donghi, Tulio. Tradición política española e ideología revolucionaria de Mayo. Buenos Aires: Centro Editor de América Latina, 1985.

Koselleck, Reinhart. "Historia de los conceptos y conceptos de historia". Ayer, 53 (2004): 27-45.

Reinhart Koselleck. Futuro pasado. Para una semántica de los tiempos históricos. Barcelona: Paidós, 1993.

Herrero, Fabián. "¿La revolución dentro de la Revolución? Algunas respuestas ideológicas de la élite política de Buenos Aires”. En Revolución. Política e ideas en el Rio de la Plata durante la década de 1810, Fabián Herrero compilador, 101-122. Ediciones Cooperativas: Buenos Aires, 2004.

Herrero, Fabián, Movimientos de Pueblo. La politica en Buenos Aires luego de 1810. Rosario: Prohistoria Ediciones, 2012.

Iramain, Pablo Sebastián. "El proceso de independencia a través de las familias principales. Tucumán entre 1810 y 1820”. En Representaciones, sociedad y poder. Tucumán en la primera mitad del siglo XIX, Irene García de Saltor y 
Cristina del Carmen López compiladoras, 63-82.Tucumán: Facultad de Filosofía y Letras/Universidad Nacional de Tucumán, 2005.

Luzuriaga Contrera, Juan Carlos. La reconquista de Buenos Aires. El cenit de Montevideo colonial, Montevideo, Planeta, 2017.

Murga, Ventura. "Las invasiones inglesas y Tucumán”. Revista de la Junta de Estudios Históricos de Tucumán I, no.1 (1968):123-138.

Navarro, Andrea Mariana. Ciudades de Andalucía. Paisajes e Imágenes. Siglos XIII-XVII. Madrid: Comité Español de Ciencias Históricas/ Dykinson, 2017.

Páez De La Torre, Carlos (h). Historia de Tucumán. Buenos Aires: Plus Ultra, 1987.

Páez De La Torre, Carlos (h) y Peña De Bascary, Sara. Porteños, provincianos y extranjeros en la batalla de Tucumán. Buenos Aires: CIUDAD/Emecé, 2012.

Parolo, María Paula. "La construcción de la fiscalidad provincial en la primera mitad del siglo XIX. Tucumán, 1814-1854", En Estado, impuestos y contribuyentes. La construcción del sistema fiscal en Tucumán en el siglo XIX, Paula Parolo y Claudia Herrera compiladoras, 15-53. Rosario: Prohistoria, 2016.

Pasino, Alejandra. "Argentina/Río de la Plata". En Diccionario Politico y Social del mundo Iberoamericano. Conceptos políticos fundamentales, 1770-1870 [Iberconceptos II], Javier Fernández Sebastián, Javier director, 33-48. Madrid: Universidad del País Vasco/Centro de Estudios Políticos y Constitucionales, 2014.

Portillo Valdés, José María. Revolución de Nación. Orígenes de la cultura constitucional en España, 1780-1812. Madrid: Boletín Oficial del Estado/Centro de Estudios Políticos y Constitucionales, 2000.

Portillo Valdés, José María. "Independencia constituyente". En Las declaraciones de independencia. Los textos fundamentales de las independencias americanas, Alfredo Ávila, Jordana Dym y Erika Pani coordinadores, 479-500. México DF: El Colegio de México/ Universidad Autónoma de México, 2013.

Reales, Lucio. Tucumán y las invasiones inglesas. San Miguel de Tucumán: Ediciones Fegamar, 1987.

Jaime Rodríguez O. La independencia de la América Española. México: El Colegio de México/Fondo de Cultura Económica, 1996. 
Serulnikov, Sergio. "El Alto Perú en la independencia del Río de la Plata". En Crear la Independencia. Historia de un problema argentino, Gabriel Entin editor, 95-125. Buenos Aires: Capital Intelectual, 2016.

Soux Muñoz Reyes, María Luisa. "La Audiencia de Charcas y los acontecimientos de 1808: rumores y tensiones en una sociedad provincial". En Las experiencias de 1808 en Iberoamérica, Alfredo Ávila y Pedro Pérez Herrero compiladores, 465-489. México: Universidad de Alcalá/Universidad Autónoma de México, 2008.

Ternavasio, Marcela. Historia de la Argentina, 1806-1852. Buenos Aires: Siglo XXI Editores, 2009. Ternavasio, Marcela. "De la crisis del poder virreinal a la crisis del poder monárquico. Buenos Aires, 1806-1810". En En el umbral de las revoluciones hispánicas. El bienio 1808-1810, México/Madrid, Roberto Breña coordinador, 265-299. México DF: El Colegio de México/Centro de Estudios Políticos y Constitucionales, 2010.

Tío Vallejo, Gabriela. "Campanas y fusiles, una historia de Tucumán en la primera mitad del siglo XIX”. En La república extraordinaria. Tucumán en la primera mitad del siglo XIX, Gabriela Tío Vallejo, coordinadora, 21-78. Rosario: Prohistoria, 2011.

Tío Vallejo, Gabriela. Antiguo Régimen y Liberalismo. Tucumán, 1770-1830. San Miguel de Tucumán: Facultad de Filosofía y Letras/ Universidad Nacional de Tucumán, 2001.

Wasserman, Fabio. Juan José Castelli. De súbdito de la corona a líder revolucionario. Buenos Aires: Edhasa, 2011.

Wasserman, Fabio. "El concepto de nación y las transformaciones del orden político en Iberoamérica. 1750-1850". Iberoamericana. Anuario de Historia de América Latina. Jahrbuch für Geschichte Lateinamerikas, no.45 (2008):197220. 